\title{
Tool for the Optimization of the Sizing and the Outline of District Heating Networks using a Geographic Information System: Application to a Real Case Study
}

\author{
Thibaut Résimont $^{a}$, Olivier Thomé ${ }^{b}$, Eva Joskin ${ }^{c}$ and Pierre Dewallef ${ }^{d}$ \\ ${ }^{a}$ University of Liège - Thermodynamics laboratory, Liège, Belgium, thibaut.resimont@uliege.be \\ ${ }^{b}$ University of Liège - Thermodynamics laboratory, Liège, Belgium, o.thome@uliege.be \\ ${ }^{c}$ University of Liège - Thermodynamics laboratory, Liège, Belgium, ejoskin@uliege.be \\ ${ }^{d}$ University of Liège - Thermodynamics laboratory, Liège, Belgium, p.dewallef@uliege.be
}

\begin{abstract}
:
District heating networks are used to provide heat to a set of consumers in a centralized way by using existing or new heating sources. These networks can include various types of heating sources and have the potential to facilitate the integration of renewable sources into the energy mix. The main drawback of this technology remains the initial investment expenditure required to build the network by connecting the heating producers to the consumers with buried pipes. Decision tools assessing the optimal network scenario in any new given geographic area are useful to provide certainty for investors and to prove to policymakers the utility of heating networks in the energy transition.

In this paper, a decision tool connected to a geographic information system (GIS) for the optimization of the outline and the sizing of district heating networks is presented. This decision tool aims to maximize the net cash flow generated by the potential heating network from user-defined economic and physical parameters. The sizing of the optimal heating sources to install or use at specific locations and the definition of the outline of the network are achieved using a mixed-integer linear programming model. The model is applied to a big case study in the city of Herstal, Belgium for a district heating network project connected to a waste incinerator for the feeding of about 2000 streets including various types of consumers like houses, apartments and offices but also a greenhouse of $10,000 \mathrm{~m}^{2}$.
\end{abstract}

\section{Keywords:}

District Heating, Geographic Information System, Mixed-Integer Linear Programming, Multi-period, Outline, Sizing.

\section{Introduction}

District heating is an efficient way to decarbonise energy systems by using alternative heating sources with lower greenhouse gases emissions [1]. The way to connect heating consumers to these sources relies on the building of pipes carrying hot pressurised water into the network. The building of these pipes represents an important part of the initial investment costs such that investors and policymakers are sometimes reluctant to invest in heating network projects. There is therefore a need to develop viable quantitative methodologies assessing the environmental and economic potential to build a network into a given geographic area. Optimization models taking into account some constraints linked to the outline and the design of heating networks exist in the literature and a non-exhaustive list of these models is summarized in Table 1.

Table 1: Review of the existing optimization methods

\begin{tabular}{lccccccc}
\hline Authors & Objective function & Linear & Outline & Sizing & $\begin{array}{c}\text { Multi- } \\
\text { period }\end{array}$ & Storage & GIS \\
\hline Apostolou [2] & $\min C_{\text {tot }}$ & $\mathbf{x}$ & $\checkmark$ & $\checkmark$ & $\checkmark$ & $\checkmark$ & $\mathbf{x}$ \\
Bertrand [3] & maxprofits & $\checkmark$ & $\mathbf{x}$ & $\checkmark$ & $\checkmark$ & $\mathbf{x}$ & $\checkmark$ \\
Bordin [4] & maxprofits & $\checkmark$ & $\checkmark$ & $\mathbf{x}$ & $\mathbf{x}$ & $\mathbf{x}$ & $\mathbf{x}$ \\
\hline
\end{tabular}




\begin{tabular}{|c|c|c|c|c|c|c|c|}
\hline Dorfner [5] & $\min C_{t o t}$ & $\checkmark$ & $\checkmark$ & $\checkmark$ & $\checkmark$ & $x$ & $\checkmark$ \\
\hline Falke [6] & $\min C_{t o t} \& C O_{2}$ & $x$ & $\checkmark$ & $x$ & $\checkmark$ & $\checkmark$ & $x$ \\
\hline Fazlollahi [7] & $\min C_{t o t} \& C O_{2}$ & $x$ & $\checkmark$ & $\checkmark$ & $\checkmark$ & $\checkmark$ & $\checkmark$ \\
\hline Haikarainen [8] & $\min C_{t o t}$ & $\checkmark$ & $\checkmark$ & $\checkmark$ & $\checkmark$ & $\checkmark$ & $x$ \\
\hline Jebamalai [9] & $\min C_{t o t}$ & $\checkmark$ & $\checkmark$ & $x$ & $\checkmark$ & $\checkmark$ & $\checkmark$ \\
\hline Mertz [10] & $\min C_{t o t}$ & $x$ & $\checkmark$ & $\checkmark$ & $x$ & $x$ & $x$ \\
\hline Molyneaux [11] & $\min C_{t o t} \& C O_{2}$ & $x$ & $x$ & $\checkmark$ & $x$ & $x$ & $x$ \\
\hline Omu [12] & $\min C_{t o t}$ & $\checkmark$ & $x$ & $\checkmark$ & $\checkmark$ & $\checkmark$ & $x$ \\
\hline Samsatli [13] & $\min C_{t o t}$ & $\checkmark$ & $\checkmark$ & $x$ & $\checkmark$ & $\checkmark$ & $x$ \\
\hline Soderman [14] & $\min C_{t o t}$ & $\checkmark$ & $\checkmark$ & $\checkmark$ & $\checkmark$ & $\checkmark$ & $x$ \\
\hline $\begin{array}{l}\text { Van Der Heijde } \\
{[15]}\end{array}$ & $\min C_{t o t} \& \mathrm{PEI}$ & $\checkmark$ & $x$ & $\checkmark$ & $\checkmark$ & $\checkmark$ & $x$ \\
\hline Weber [16] & $\min C_{t o t} \& C O_{2}$ & $x$ & $\checkmark$ & $\checkmark$ & $\checkmark$ & $\checkmark$ & $\checkmark$ \\
\hline $\begin{array}{l}\text { Model in this } \\
\text { paper }\end{array}$ & $\max N C F$ & $\checkmark$ & $\checkmark$ & $\checkmark$ & $\checkmark$ & $\checkmark$ & $\checkmark$ \\
\hline
\end{tabular}

All these models present specific features enabling for example to take into account urban planning constraints with a geographic information system or the integration of thermal storage capacity to shift the heating production from one time period to another. However, these models are generally limited to small-scale case studies and at least one of the main features addressed in Table 1 is missing. The aim of this paper is thus to define and present a new decision tool based on a mixedinteger linear programming model and connected to a geographic information system. This userdefined decision tool is intended for the outline and design of a new or existing network in any geographic area of small or big size.

\section{Methodology}

The strategic planning of these networks is based on the maximization of the net cash flow of a potential district heating project. The decision tool retrieves information from a geographic information system listing all streets and dwellings into a prescribed geographic area. This geographic information system combined to a cadastral matrix of the area enables to determine the hourly heating demand of each dwelling constitutive of the studied neighbourhood. A selection of representative timesteps out of the hourly heating consumption profile is then achieved to reduce the computation time of the decision tool. These representative heating consumption profiles combined with userdefined economic and design parameters are used as inputs of the optimization model implemented in Julia language. The aim of the optimization model relies on the maximization of the net cash flow of the optimal heating network. The decision tool provides then as outputs the main economic and design data with a layout of the network into the geographic information system.

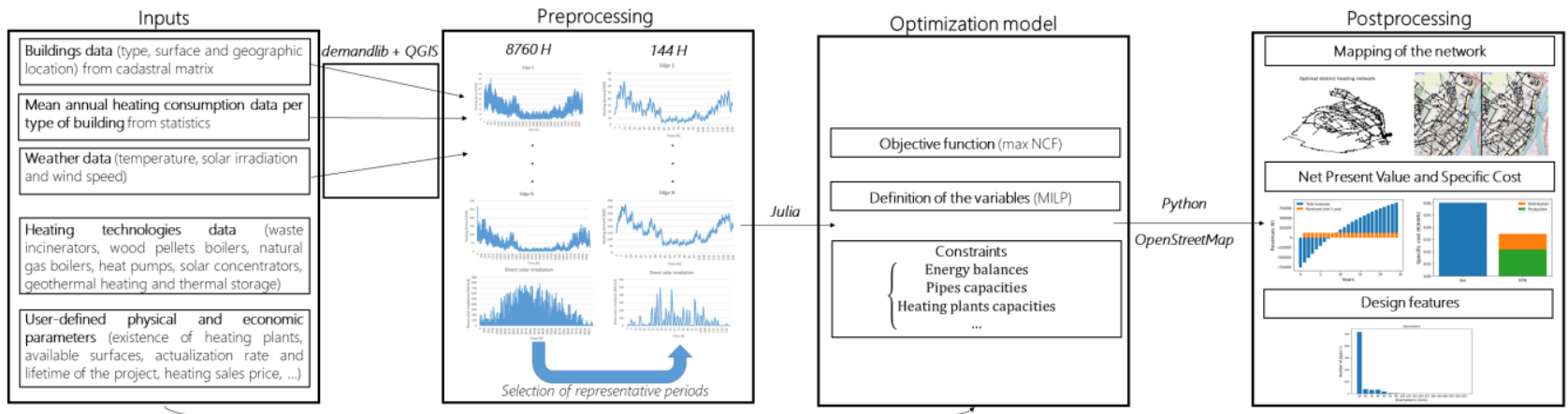

Fig. 1. Framework of the decision tool for the strategic planning of a district heating network. 


\subsection{Processing of the heating demands}

\subsubsection{Collection of annual heating demand data}

A listing of all the features linked to the dwellings constitutive of the studied area into the geographic information system requires data collection from a cadastral matrix of this area. This cadastral matrix gives some features of each dwelling like the kind of dwelling, its total area and its location which are used for the computation of their annual and hourly heating demand. The assessment of the annual heating demand of a given type of dwellings relies on statistics data identifying the total consumption in Belgium of each type of dwellings $\dot{Q}_{\text {heat,tot }}^{a}$ and the living surface of the $n_{a}$ dwellings of type $a$ in Belgium. The heating demand per unit surface of a dwelling of type $a$ is thus defined by (1).

$\dot{Q}_{\text {heat }, m^{2}}^{a}\left[\frac{k W h}{m^{2} \cdot \text { year }}\right]=\frac{\dot{Q}_{\text {heat }, \text { tot }}^{a}}{\sum_{l=1}^{n_{a}} S_{l}^{a}}$

where

$S_{l}^{a}=S_{\text {floor }, l^{\cdot}}^{a}\left(n_{\text {floors }}+\delta\right)$ with $\delta=\left\{\begin{array}{c}0 \text { if non habitable attic } \\ 1 \text { if habitable attic }\end{array}\right.$

For any dwelling $l$ of type $a$ constitutive of the studied area, its annual heating consumption is finally determined by (3) where the total living area $S_{l}^{a}$ is computed from the floor area $S_{\text {floor }, l}^{a}$ identified into the geographic information system.

$\dot{Q}_{\text {heat }, l}^{a}[k W h /$ year $]=S_{l}^{a} \cdot \dot{Q}_{\text {heat }, m^{2}}^{a}$

These annual heating demand values are then used to generate hourly heating demand profiles for each dwelling.

\subsubsection{Generation of hourly heating demands profiles}

The sizing of a district heating network generally requires an accurate knowledge of the hourly heating demands of the dwellings constitutive of the studied neighbourhood or city. The main difficulty related to the computation of these heating demands is generally due to the large amount of dwellings into a specific geographic area. Detailed physical models of dwellings have thus some limitations in terms of computational time for the modelling of the heating consumption of a large building stock. An alternative to the use of physical models for the computation of heating consumption relies on the use of synthetic heating load profiles and temperature forecasts for different kinds of dwellings. Some open-source frameworks are already available to design these kinds of heating profiles. A Python library, named Oemof, based on synthetic heating load profiles from the $B D E W[17]$ is used. This framework retrieves the annual heating consumption of a dwelling $\dot{Q}_{\text {heat }, l}^{a}$ from the geographic information system to create a new hourly heating demand profile. Synthetic heating load profile is described by a transfer function $T F$ represented by Eq. (4).

$T F\left(\theta_{g e o, t}\right)=\left[\frac{A}{1+\left(\frac{B}{\theta_{g e o, t}-\theta_{0}}\right)^{C}}+D\right], \theta_{0}=40^{\circ} \mathrm{C}$

where A, B, C and D are the parameters of the transfer function and are dependent on the kind of dwellings.

$\theta_{\text {geo }}$ represents the geometric mean temperature defined by the following equation for a prescribed time period $t$.

$\theta_{g e o, t}=\frac{T_{t}+\frac{1}{2} \cdot T_{t-1}+\frac{1}{4} \cdot T_{t-2}+\frac{1}{8} \cdot T_{t-3}}{1+\frac{1}{2}+\frac{1}{4}+\frac{1}{8}}$

with $T_{t-3}, T_{t-2}, T_{t-1}$ and $T_{t}$ are the respective temperatures from the time period $t-3$ to the time period $t$.

The heating consumption for a time period $t$ can be thus computed with the following equation.

$\dot{Q}_{\text {heat }, l, t}^{a}=T F\left(\theta_{g e o, t}\right) \cdot F_{w d} \cdot K W_{l}$ 
$F_{w d}$ is a factor dependent on the day of the week and $\mathrm{KW}$ is a constant characterizing the consumer which is defined by the heating demand of this consumer and the transfer function:

$K W_{l}=\frac{\sum_{t=1}^{N_{\text {timesteps }}} \dot{Q}_{\text {heat }, l, t}^{a}}{\sum_{t=1}^{N_{\text {timesteps }}} T F\left(\theta_{\text {geo }, t}\right)}=\frac{\dot{Q}_{\text {heat }, l}^{a}}{\sum_{t=1}^{N_{\text {timesteps }}} T F\left(\theta_{\text {geo }, t}\right)}$

From the annual heating consumption of a dwelling $l$ of type $a$ during a year $\dot{Q}_{\text {heat }, l}^{a}$ and a weather file with all the hourly temperatures during a year for a characteristic year in Belgium, heating load profiles for different kinds of dwellings can be then directly computed.

\subsection{Selection of representative periods}

The large number of optimization variables defined with hourly heating consumption data can be decreased using representative periods to reduce the computation time of the decision tool. These representative periods have to be selected in order to represent as accurately as possible the heating demand profile over the whole year with a limited number of timesteps. Generally, these periods are chosen to fit as well as possible the load duration curve but do not include extreme periods with peak demands. In the decision tool presented in this paper, a procedure based on an optimization approach developed by [18] is readjusted to sort selected representative periods and to include peak demands in order to represent more accurately the dynamics of the heating demand. The objective of the optimisation procedure consists of minimizing the deviation between the load duration curve of the full year period and its representation by the means of a selected number of representative days with assigned weights. The weight of each representative period is used to scale the variable costs assessed into the optimization objective.

The method developed by Poncelet et al. [18] has the disadvantage to select the best fitting time periods of the load duration curve without really representing peak demands and the dynamics of the system which is essential for its sizing. Indeed, for example, the sizing of a storage depends on the dynamics of the loading and unloading phases during the different time periods. Van Der Heijde [19] developed a sorting procedure for the different selected representative periods. However, this new synthetic chronological representation of a year does not include peak demands which are also important to consider for the sizing of heating sources and storages. Moreover, even with the selection of only a few representative days, the number of optimization variables can quickly increase exponentially with the number of selected representative days. In order to overcome this problem, a new procedure based on the selection approach developed by Poncelet has been developed as illustrated in Fig. 2.

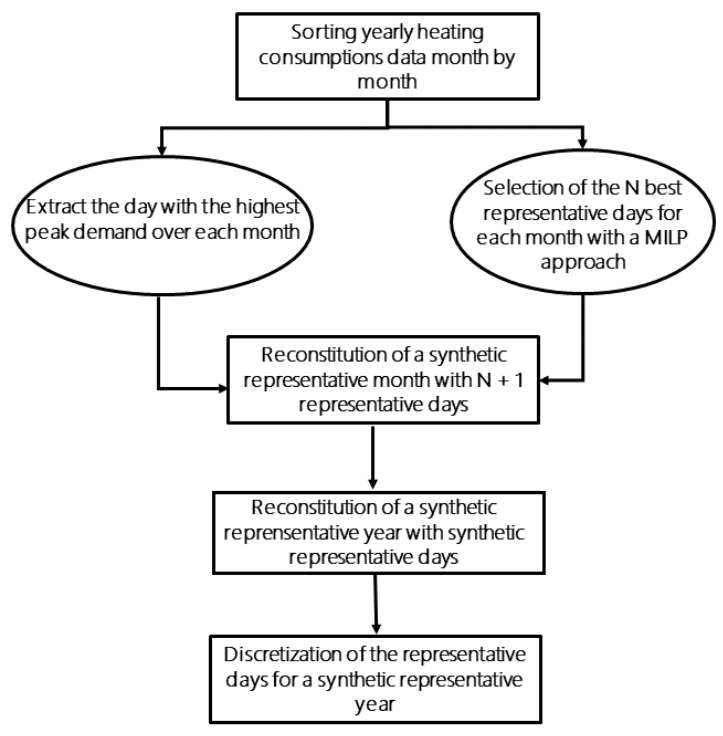

Fig. 2. Procedure for the selection of representative periods. 
In this procedure, instead of selecting the best representative days over the whole year, a preprocessing over heating consumption data is achieved to sort heating consumptions on a monthly basis. For each month, the day with the biggest hourly demand is directly chosen with a unitary weight as a representative day representing the peak demand of the month. The optimization procedure developed by Poncelet is used to select the best fitting $N_{\text {repr,month }}$ days for each month. For each month, $N_{\text {repr,month }}+1$ days are thus chosen to finally reshape a synthetic year with 12. $\left(N_{\text {repr,month }}+1\right)$ representative days. For a given hourly heating consumption profile, the procedure gives the results illustrated in Fig. 3(a). In order to reduce even more the number of timesteps for the optimization process, a discretization of the representative days in $N_{\text {repr,hours }}$ bins is achieved by using KBinsDiscretizer tool [20] in Python. The discretization of a selected representative day is illustrated in Fig. 3(b).

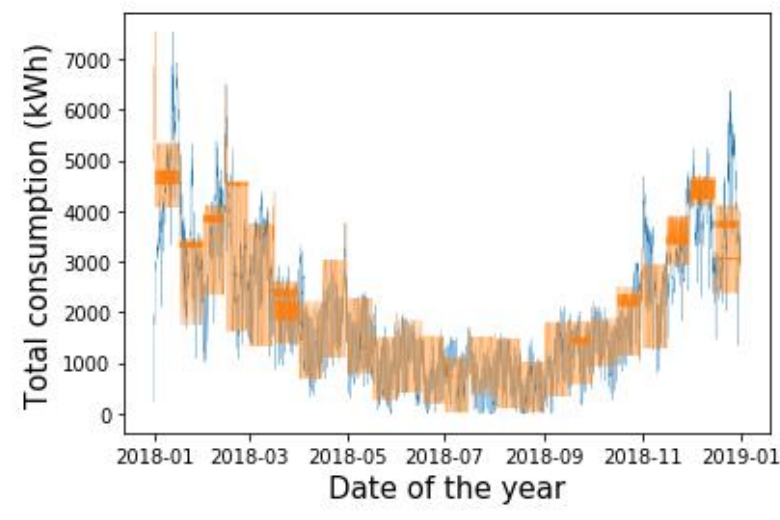

(a)

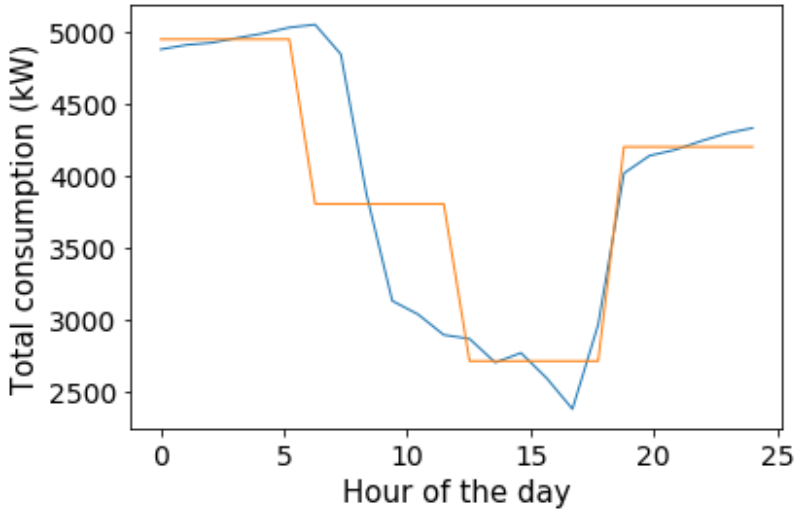

(b)

Fig. 3. (a) Heating demand of a real year (blue) and a representative year (orange). (b) Discretization of a representative day with 4 representative hours $\left(N_{\text {repr,hours }}=4\right)$.

\subsection{Optimization model}

The optimization model used in the decision tool relies on a mixed-integer linear programming formulation with a maximization of the net cash flow as an objective function. The model is based on a graph representation of the studied neighbourhood such that edges of the graph match with the streets of the considered geographic zone and their intersections are represented by the nodes of the graph. A small neighbourhood with only a few streets can be represented as in Fig. 4.

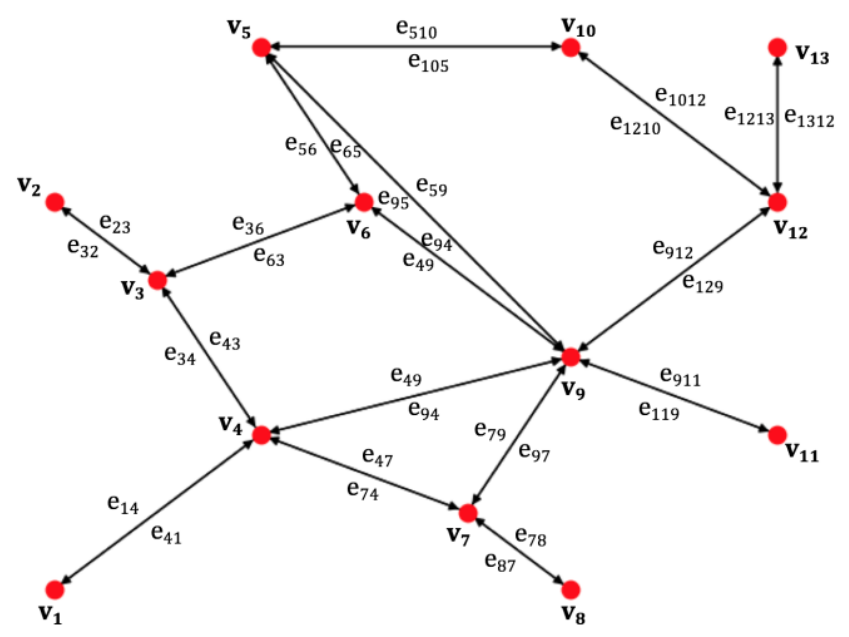

Fig. 4. Graph representation of a neighbourhood.

From this graph representation, a set of vertices and edges can be defined such that mass and energy balance equations with some constraints are applied on this network. 


\subsubsection{Sets}

Different sets have to be defined.

- V : Set of vertices listing the intersections of the streets

- $\mathrm{V}_{\mathrm{P}} \subseteq \mathrm{V}:$ Set of potential heating sources and thermal storages locations

- $\mathrm{H}$ : Set of heating production technologies for a specific heating location

\subsubsection{Variables}

Table 2. Continuous and discrete variables of the MILP problem

$\dot{P}_{j, t}^{\text {in }} \in \mathbb{R}_{0}^{+}$: Incoming power flow during timestep $t$ in edge $j[\mathrm{~kW}]$

$\dot{P}_{j, t}^{\text {out }} \in \mathbb{R}_{0}^{+}$: Outcoming power flow during timestep $t$ in edge $j[\mathrm{~kW}]$

$\dot{P}_{j}^{\max } \in \mathbb{R}_{0}^{+}:$Maximum incoming power flow in edge $j$ over all the timesteps $[\mathrm{kW}]$

$\dot{Q}_{j, t}^{\text {loss }} \in \mathbb{R}_{0}^{+}$: Heat losses during timestep $t$ in edge $j[\mathrm{~kW}]$

$\dot{Q}_{i, t}^{\text {prod }} \in \mathbb{R}_{0}^{+}:$Power production during timestep $t$ at vertex $i[\mathrm{~kW}]$

$\dot{Q}_{k, m, t}^{\text {source,tech }} \in \mathbb{R}_{0}^{+}$: Power production during timestep $t$ at heating location $k$ with heating technology $m[\mathrm{~kW}]$

$\dot{Q}_{k, m}^{\text {max,source,tech }} \in \mathbb{R}_{0}^{+}$: Maximum power production at heating location $k$ with heating technology $m$ [kW or $\mathrm{kWh}]$

\subsubsection{Objective function and constraints}

The objective of the decision tool relies on the maximization of the net cash flow (NCF) generated from a district heating project. The resulting simplified mathematical model follows.

$\max N C F=R_{\text {heat }}-\left(f_{C A P E X} \cdot C_{C A P E X}+f_{O P E X} \cdot C_{O P E X}\right)$

subject to

$\forall e_{j} \in E, t \in T: P_{j, t}^{\text {out }}=P_{j, t}^{\text {in }}-u_{j, t} \cdot p_{j}^{\text {connected }} \cdot \dot{Q}_{j, t}^{\text {heat }}-\dot{Q}_{j, t}^{\text {loss }}$

$\forall v_{i} \in V, t \in T: \quad \sum_{j^{i} \in N_{i}}\left(P_{j^{i}, t}^{\text {in }}-P_{j^{i}, t}^{\text {out }}\right)=\dot{Q}_{i, t}^{\text {prod }}+\dot{Q}_{i, t}^{\text {unload }}-\dot{Q}_{i, t}^{\text {load }}$

$\forall v_{i} \in V, t \in T: \quad \sum_{k \in V_{P}} s_{i, k} \cdot\left(\dot{Q}_{i, t+1}^{s t o}-\left(1-w_{t} \cdot \alpha_{k}^{\text {loss }}\right) \cdot \dot{Q}_{i, t}^{\text {sto }}-w_{t} \cdot \dot{Q}_{i, t}^{\text {load }}+w_{t} \cdot \dot{Q}_{i, t}^{\text {unload }}\right)=0$

$\forall e_{j} \in E: P_{j}^{\max } \leq x_{j} \cdot \dot{Q}_{j}^{\max , e d g e}$

$\forall e_{j} \in E, t \in T: P_{j, t}^{\text {in }} \leq P_{j}^{\max }$

$\forall k \in V_{P}, m \in K: \dot{Q}_{k, m}^{\text {max,source,tech }} \leq \dot{Q}_{k, m}^{\text {limit,source,tech }}$

$\forall k \in V_{P}, m \in K, t \in T: \dot{Q}_{k, m, t}^{\text {source,tech }} \leq C F_{t, m} \cdot \dot{Q}_{k, m}^{\text {max,source,tech }}$

$\forall e_{j} \in E, t \in T: x_{j} \geq m_{j}^{\text {build }}$

$\forall e_{j} \in E, t \in T: u_{j, t} \leq x_{j}$

$\forall e_{j} \in E, t \in T: u_{j, t}+u_{j^{*}, t} \leq 1$ 
The objective function (8) of the problem aims to maximize the net cash flow by computing all the capital and operating expenses linked to the project and deducting all the incomes from heating sales. The constraints of the model can be sorted in 3 main categories. The first one includes the energy balances at the vertices and over the edges of the graph represented by (9), (10) and (11). A second category of constraints defines the limited capacities of the potential heating locations and the potential pipes which are constrained by (12)-(15). The final one takes into account design constraints making mandatory to build and use (or not) some pipes as prescribed by (16)-(18).

\section{Case study}

The case studied in this paper considers a geographic area in the city of Herstal in Belgium where a new district heating project using a waste incinerator as heating source is currently implemented. A graph representation of the studied area and its heating source is given in Fig. 5(a). The area is made up of 1780 streets with a representative graph related to this area of 3560 edges and 1296 nodes.
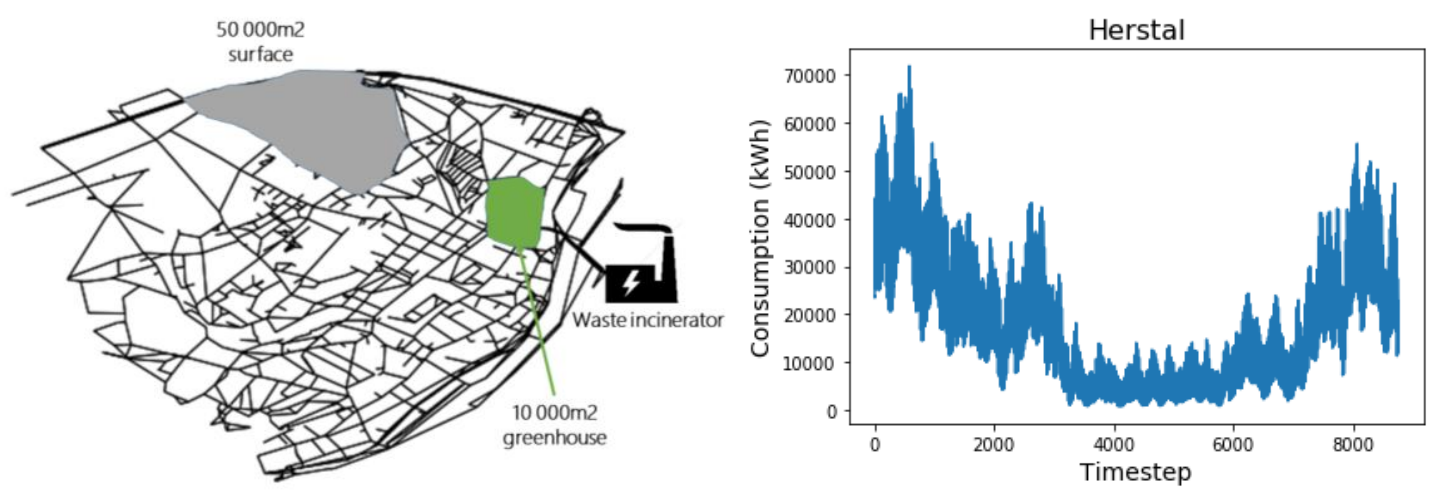

Fig. 5. Graph representation of Herstal area and its total heating consumption.

The district heating project will use the waste incinerator to feed the neighbourhood made up of dwellings of different kinds but also of a future greenhouse of $10,000 \mathrm{~m}^{2}$ which could be built in the following years. The initial project relies on the waste incinerator as the unique heating source with a prescribed constant heating production cost of $0.03 € / \mathrm{kWh}$ but additional new heating sources could be considered by using existing available surfaces as illustrated in Fig. 5(a) with a surface of 50,000 $\mathrm{m}^{2}$. The waste incinerator which will be used for the feeding of the district heating network currently produces only electricity from the exhaust gases coming out of the waste incineration process. This electricity is sold over the electricity network. This incinerator is going to be upgraded into a combined heat and power plant whose thermal capacity is limited to a maximum value of $100 \mathrm{MW}_{\text {th }}$. Using a representative year with 144 timesteps (36 representative days with 4 representative hours per day), the number of variables of the optimization problem is counted to 2,806,777 variables. The use of the decision tool on this real case study with different scenarios can thus give some useful results and trends to help the stakeholders of the heating network project.

\subsection{Influence of the greenhouse as new heating consumer on the network}

The first scenario consists in studying the influence of the integration of a $10,000 \mathrm{~m}^{2}$ greenhouse on the outline and the design of an economically optimal heating network. The greenhouse could be an interesting consumer to integrate into a network thanks to its little fluctuating heating consumption all over the year and especially non zero heating demand during the summer. The optimization formulation presented in this paper has thus been used to determine the outline and design of the optimal heating network that could be built into the studied area. A project lifetime of 30 years with a constant heating sales price of $0.07 € / \mathrm{kWh}$ is considered assuming that all the potential consumers over a given street would be connected to the network if a pipe is built into this street $\left(p_{j}^{\text {connected }}=\right.$ 1). Results concerning the influence on the sizing of the network for the integration of a greenhouse are summarized in Table 3. It can be noticed that the prescribed heating sales price relies on the main competitive heating solution on the market which is the gas solution, the market price of which is given in [21] for different countries in the European Union. This enables to provide a fair comparison between a centralized and decentralized way of heating production. 
Table 3. Main outputs from the optimization model for a case without and with a greenhouse

\begin{tabular}{lll}
\hline & Without a greenhouse & With a greenhouse \\
\hline Used heating capacity $\left(\mathrm{MW}_{\text {th }}\right)$ & 62.817 & 62.946 \\
CAPEX $(\mathrm{M} €)$ & 57.102 & 57.140 \\
OPEX $(\mathrm{M} €)$ & 145.930 & 146.562 \\
Revenues $(\mathrm{M} €)$ & 315.618 & 317.054 \\
Profits $(\mathrm{M} €)$ & 112.586 & 113.352 \\
\hline
\end{tabular}

The connection of the greenhouse to the network slightly increases the capital and operating expenses linked respectively to the building of a new pipe and substation to connect the greenhouse to the network while increasing the total heating production to supply the additional heating demand of the greenhouse. The decision tool also determines the mapping of the optimal heating network, which is represented in Fig. 6(b), based on a graph representation of the studied area represented in Fig. 6(a). It can be observed from Fig. 6(b) that most streets (806 out of 866 streets), depicted in black, are connected to the network while some ones, depicted in red, are not integrated into the heating network because they are assessed to be non-economically profitable to connect. These streets are related to additional investment and operating costs that are not counterbalanced by the revenues generated from the heating sales. These streets, depicted in red, which are not connected to the network are generally characterized by a relatively low heating demand compared to other streets such that a decentralized heating production using gas boilers or another heating technology would be more profitable that a connection to the heating network for a centralized way of heating supply.

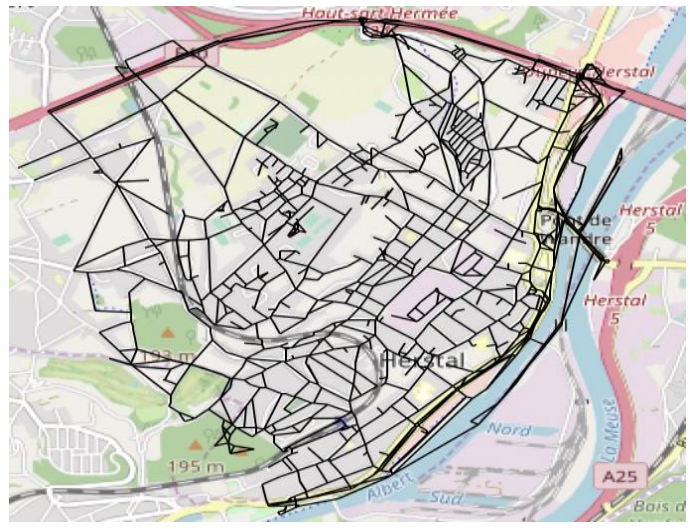

(a)

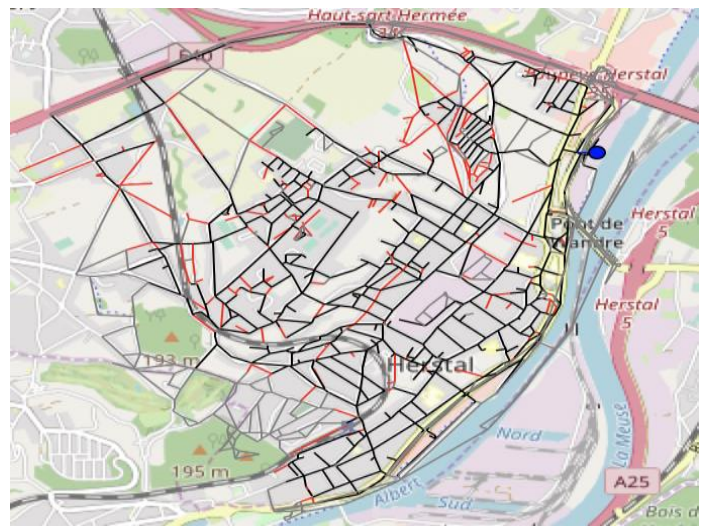

(b)

Fig. 6. (a) Graph representation of the area. (b) Optimal heating network with the greenhouse.

\subsection{Influence of the heating sales price on the network}

The optimization tool presented in this paper enables to provide a decision support to the stakeholders linked to heating network projects defining inputs parameters specific to each studied area and based on the market conditions. The previous scenario considered a market price equivalent to the current gas price on the market. However, this status quo market price is not necessarily a sufficient condition for heating consumers to change their heating production supply from a gas network to a heating network. The influence of the heating sales price on the economically optimal heating network has thus to be taken into account by the stakeholders to assess the streets which remain profitable to supply for a lower heating sales price.

A parametric study decreasing the heating sales price from $0.07 € / \mathrm{kWh}$ to $0.04 € / \mathrm{kWh}$ enables to show the influence of the heating sales price on the outline of the heating network as represented in Fig. 7. The decrease of the heating sales price reduces the number of streets (depicted in black) to connect to the network to guarantee an optimal economic profitability. Indeed, some streets which were interesting consumers to connect are no more profitable because their heating consumption does not ensure a sufficient return on investment compared to the investment costs required to connect these streets to the network. The number of connected streets decreases from 806 streets to 647 streets for a decrease of the heating sales price from $0.07 € / \mathrm{kWh}$ to $0.05 € / \mathrm{kWh}$. The optimization tool also enables to determine a trade-off of the critical heating sales price of $0.04 € / \mathrm{kWh}$ below which it is no 
more profitable to build a heating network because of the too big capital and operating expenses compared to the heating sales revenues.

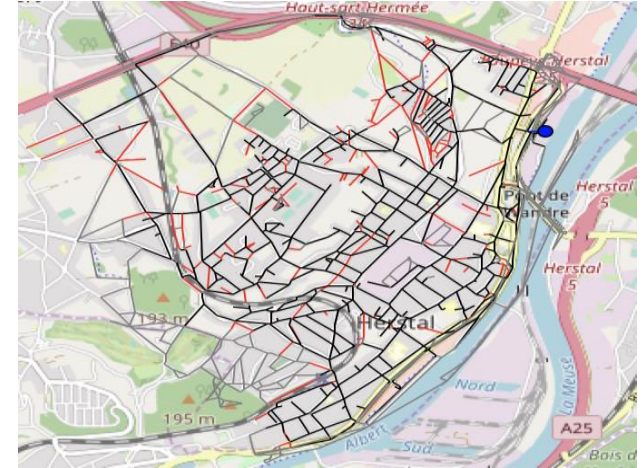

(a)

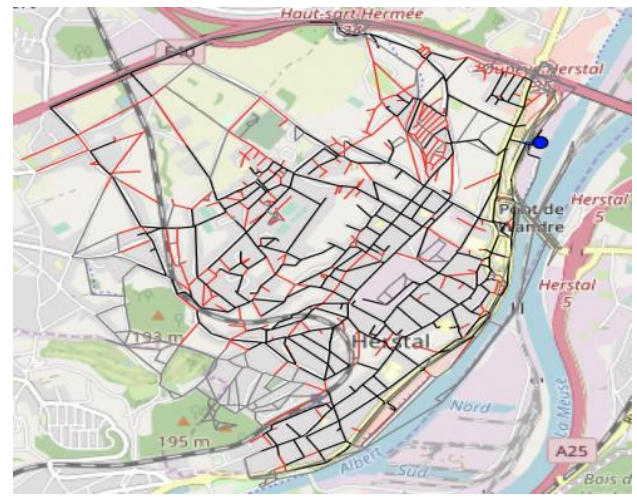

(c)

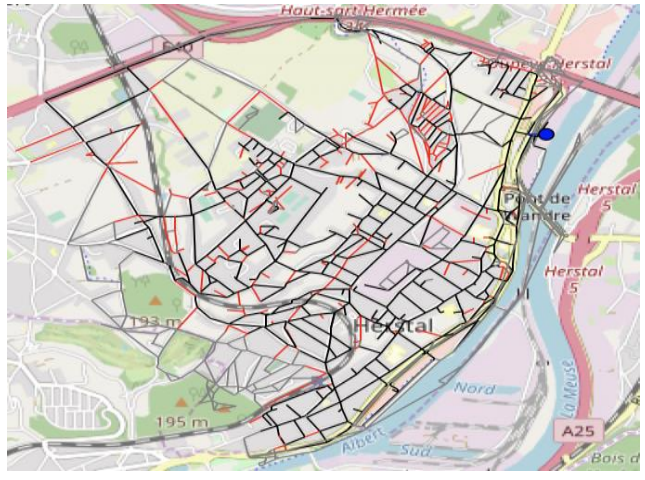

(b)

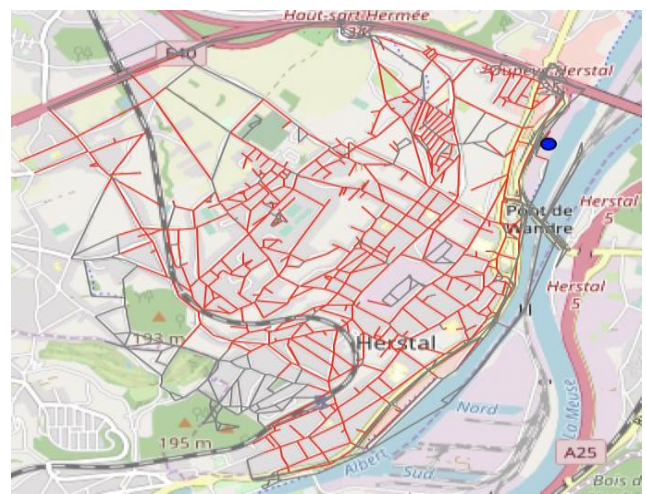

(d)

Fig. 7. Influence on the outline of the network for a heating sales price of (a) $0.07 € / \mathrm{kWh}(b)$ $0.06 € / \mathrm{kWh}$ (c) $0.05 € / \mathrm{kWh}(\mathrm{d}) 0.04 € / \mathrm{kWh}$.

The decrease of the heating sales price obviously increases the period of return on investment linked to the network project. As illustrated in Fig. 8, despite the smaller capital expenses due to a reduced number of streets connected to the network, the heating sales revenues from the network are smaller with a reduced heating sales price. Therefore, the expenses linked to the network are recovered after a longer period of time such that the period of return on investment is directly linked to this heating sales price. Indeed, a decrease of the heating sales price from $0.07 € / \mathrm{kWh}$ to $0.05 € / \mathrm{kWh}$ leads to an increase of the period of return on investment from 10 years to more than 17 years. The assessment of the optimal heating sales price enabling to guarantee a maximum connection rate of $100 \%$ to the network is thus an important step before the outline and sizing of any new heating network project. The submission of market studies to the potential heating consumers of a new heating network project remains essential to ensure consistency between the optimization model and the market reality.

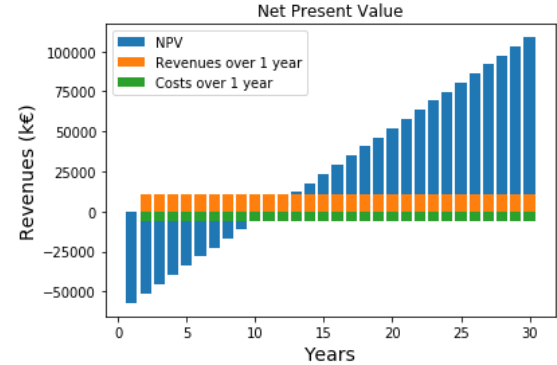

(a)

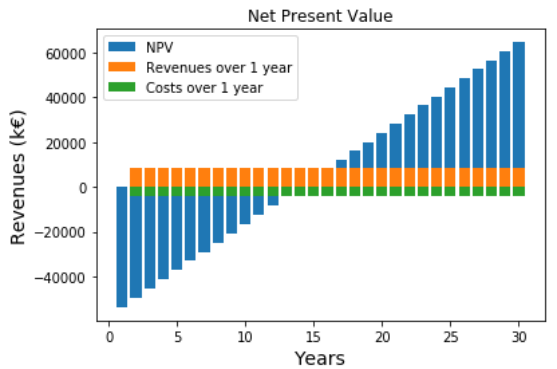

(b)

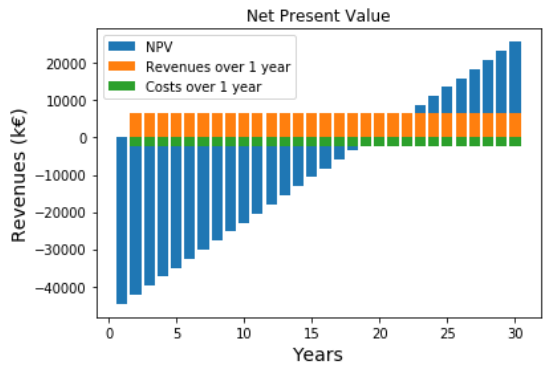

(c)

Fig. 8. Influence on the net present value of the project for a heating sales price of (a) $0.07 € / \mathrm{kWh}$ (b) $0.06 € / \mathrm{kWh}$ (c) $0.05 € / \mathrm{kWh}$. 


\subsection{Influence of the connection rate on the network}

As for the study of the influence of the heating sales price on the network, a parametric analysis concerning the connection rate into a street can be achieved in the following. In any new heating network project, this connection rate has to be taken into account to avoid to overestimate the heating revenues linked to the connection of a street to a new heating network. There is no obligation for a heating consumer to connect to a heating network even if the street is fed by a pipe of the network. For the stakeholders of a future network project, it is thus important to assess the heating load specific to each street of the network in order to design as accurately as possible the network. This heating load can be scaled by a connection rate factor assessing approximatively the number of consumers into a street which would be ready to be connected to a heating network based on previous market studies conducted with the inhabitants of the studied area. As depicted in Fig. 9, a decrease of this connection rate from $100 \%$ to $40 \%$ has a similar effect than the decrease of the heating sales price by reducing the number of streets connected to the network from 806 streets to 548 streets. Below a connection rate of $40 \%$, the building of a heating network is assessed to become no more profitable as depicted in Fig. 9(d) where all the streets are depicted in red and are then not connected to a heating network.

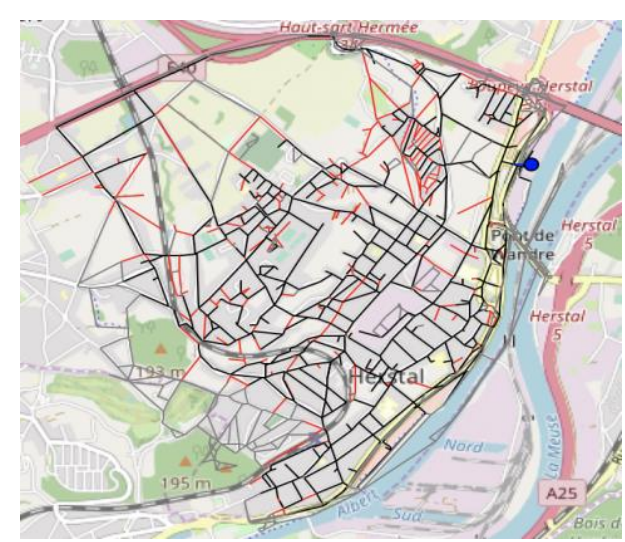

(a)

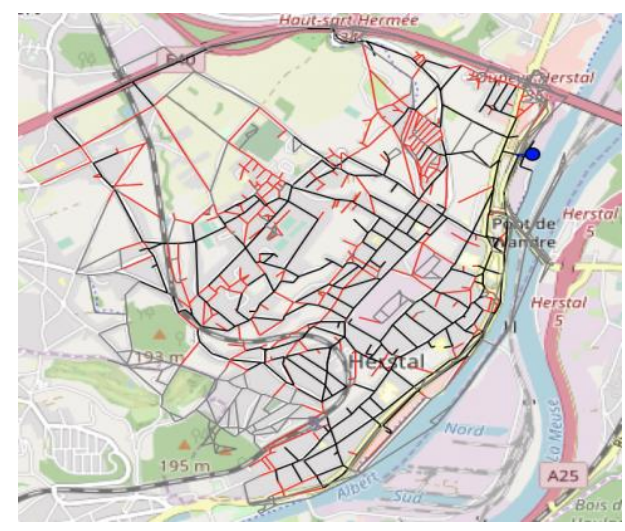

(c)

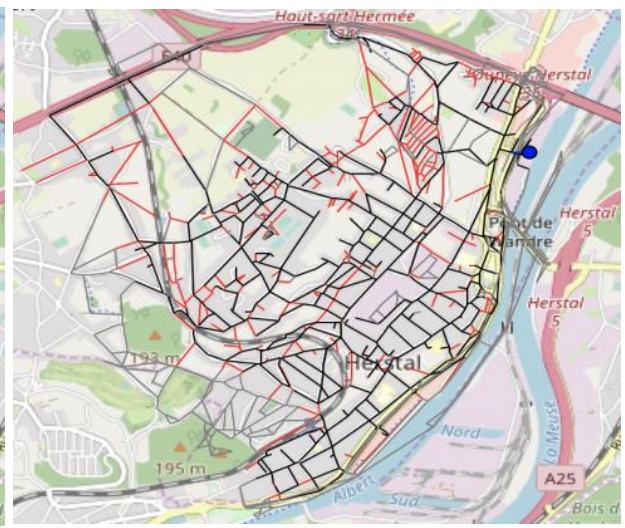

(b)

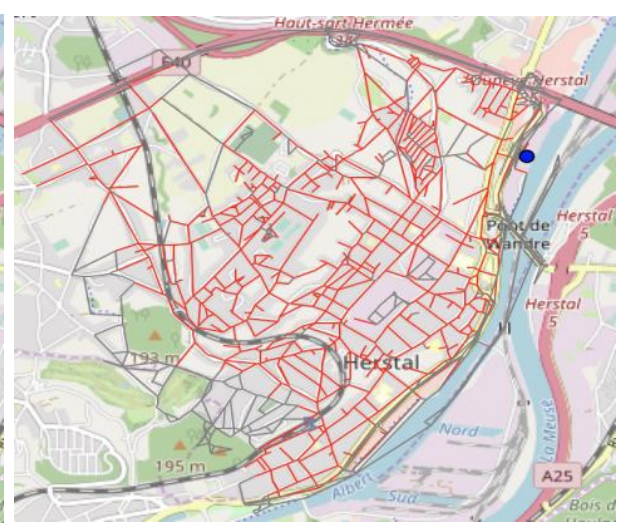

(d)

Fig. 9. Influence on the outline of the network for a connexion rate of (a) $80 \%$ (b) $60 \%(c) 40 \%(d)$ $20 \%$.

\section{Conclusion}

The optimization tool presented in this paper aims to provide a decision support to the stakeholders of a new heating network project by providing a mapping of a potential profitable heating network from a prescribed area as well as user-defined economic and physical parameters. The running of different scenarios studying the influence of some parameters on the profitability of the project enables to determine the barriers to the development of a heating network in some streets with a decrease of the values of these parameters. In this paper, the importance of the assessment of the heating sales price and the connection rate of consumers has been highlighted by 2 scenarios based on a real case. 
Indeed, the decrease of the heating sales price from $0.07 € / \mathrm{kWh}$ to $0.04 € / \mathrm{kWh}$ leads to a decrease of the number of streets connected into the network until a break-even point of $0.04 € / \mathrm{kWh}$ below which it is no more profitable to build any network. As for the heating sales price, the decrease of the connection rate of consumers implies a decrease of the number of streets connected until a minimum connection rate of $40 \%$ below which the building of a heating network is no more profitable. The tool presented in this paper aims then to quantify values of some decision parameters like the heating sales price and the connection rate of consumers for the profitability of building a heating network.

\section{Nomenclature}

\section{Symbols}

C costs, $€$

CAPEX capital expenditures, $€$

$C F \quad$ capacity factor, - or $\%$

$f \quad$ actualization factor, - or \%

GIS Geographic Information System

$m \quad$ mandatory pipe building, 0 or 1

$N \quad$ number of representative days, -

NCF Net Cash Flow, $€$

OPEX operating expenditures, $€$

$\dot{P} \quad$ power flow, $\mathrm{kW}$

$p \quad$ ratio of connected consumers, $\%$

PEI Primary Energy Import share, \%

$Q \quad$ heating content, $\mathrm{kWh}$

$\dot{Q} \quad$ heating production, $\mathrm{kW}$

$R \quad$ revenues, $€$

$s \quad$ heating source $k$ at vertex $i, 0$ or 1

$T$ temperature, ${ }^{\circ} \mathrm{C}$ or $\mathrm{K}$

$T F \quad$ transfer function, -

$u \quad$ use or not of a pipe, 0 or 1

$w \quad$ weight of a time period, -

$x \quad$ building or not of a pipe, 0 or 1

\section{Greek symbols}

$\alpha$ heat losses coefficient, -

$\theta$

temperature
difference, ${ }^{\circ} \mathrm{C}$ or
$\mathrm{K}$

\section{Subscripts and superscripts}

a

build building

geo geometric

i vertex ID

in incoming

j edge ID

$\mathrm{j}^{*} \quad$ reverse edge ID

$\mathrm{k}$ heating location ID

1 dwelling ID

m technology ID

load loading

loss heat losses

max maximum

out outcoming

prod production

repr representative

sto storage

t timestep

tech technology

tot total

unload unloading

w water

wd day of the week

\section{References}

[1] European Commission. An EU Strategy on Heating and Cooling. J Chem Inf Model 2016;53:1689-99.

[2] Apostolou M, Ghazouani S, Le Bourdiec S, Tran CT, Zoughaib A. District heating network design considering fluctuations in the demand and thermal storage means. ECOS 2018 - Proc 31st Int Conf Effic Cost, Optim Simul Environ Impact Energy Syst 2018:1-12.

[3] Bertrand A, Mian A, Kantor I, Aggoune R, Maréchal F. Regional waste heat valorisation: A mixed integer linear programming method for energy service companies. Energy 2019;167:454-68. https://doi.org/10.1016/j.energy.2018.10.152.

[4] Bordin C, Gordini A, Vigo D. An optimization approach for district heating strategic network design. Eur J Oper Res 2016;252:296-307. https://doi.org/10.1016/j.ejor.2015.12.049. 
[5] Dorfner J, Hamacher T. Large-scale district heating network optimization. IEEE Trans Smart Grid 2014;5:1884-91. https://doi.org/10.1109/TSG.2013.2295856.

[6] Falke T, Krengel S, Meinerzhagen AK, Schnettler A. Multi-objective optimization and simulation model for the design of distributed energy systems. Appl Energy 2016;184:150816. https://doi.org/10.1016/j.apenergy.2016.03.044.

[7] Fazlollahi S, Becker G, Ashouri A, Maréchal F. Multi-objective, multi-period optimization of district energy systems: IV - A case study. Energy 2015;84:365-81. https://doi.org/10.1016/j.energy.2015.03.003.

[8] Haikarainen C, Pettersson F, Saxén H. A model for structural and operational optimization of distributed energy systems. Appl Therm Eng 2014;70:211-8. https://doi.org/10.1016/j.applthermaleng.2014.04.049.

[9] Maria Jebamalai J, Marlein K, Laverge J, Vandevelde L, van den Broek M. An automated GIS-based planning and design tool for district heating: Scenarios for a Dutch city. Energy 2019;183:487-96. https://doi.org/10.1016/j.energy.2019.06.111.

[10] Mertz T, Serra S, Henon A, Reneaume JM. A MINLP optimization of the configuration and the design of a district heating network: Study case on an existing site. Energy Procedia 2017;116:236-48. https://doi.org/10.1016/j.egypro.2017.05.071.

[11] Molyneaux A, Leyland G, Favrat D. Environomic multi-objective optimisation of a district heating network considering centralized and decentralized heat pumps. Energy 2010;35:7518. https://doi.org/10.1016/j.energy.2009.09.028.

[12] Omu A, Choudhary R, Boies A. Distributed energy resource system optimisation using mixed integer linear programming. Energy Policy 2013;61:249-66. https://doi.org/10.1016/j.enpol.2013.05.009.

[13] Samsatli S, Samsatli NJ. A general mixed integer linear programming model for the design and operation of integrated urban energy systems. J Clean Prod 2018;191:458-79. https://doi.org/10.1016/j.jclepro.2018.04.198.

[14] Söderman J, Pettersson F. Structural and operational optimisation of distributed energy systems. Appl Therm Eng 2006;26:1400-8. https://doi.org/10.1016/j.applthermaleng.2005.05.034.

[15] van der Heijde B, Vandermeulen A, Salenbien R, Helsen L. Integrated optimal design and control of fourth generation district heating networks with thermal energy storage. Energies 2019;12. https://doi.org/10.3390/en12142766.

[16] Weber C, Shah N. Optimisation based design of a district energy system for an eco-town in the United Kingdom. Energy 2011;36:1292-308. https://doi.org/10.1016/j.energy.2010.11.014.

[17] Gas AVS. BDEW / VKU / GEODE- Leitfaden 2018.

[18] Poncelet K, Hoschle H, Delarue E, Virag A, Drhaeseleer W. Selecting representative days for capturing the implications of integrating intermittent renewables in generation expansion planning problems. IEEE Trans Power Syst 2017;32:1936-48. https://doi.org/10.1109/TPWRS.2016.2596803.

[19] van der Heijde B, Vandermeulen A, Salenbien R, Helsen L. Representative days selection for district energy system optimisation: a solar district heating system with seasonal storage. Appl Energy 2019;248:79-94. https://doi.org/10.1016/j.apenergy.2019.04.030.

[20] Li H, Phung D. Journal of Machine Learning Research: Preface. J Mach Learn Res 2014;39:iii.

[21] Eurostat. Statistics Explained On Natural Gas Prices in the European Union. Accessed: 202101-25.2020.https://ec.europa.eu/eurostat/statisticsexplained/index.php?title=File\%3ANatural_gas_prices_for_household_consumers\%2C_first_h alf_2020_\%28EUR_per_kWh\%29_v3.png 